\title{
EKSPLOITASI ANAK DALAM TRADISI PACUAN KUDA PADA MASYARAKAT DOMPU
}

\author{
Akbar Tanjung ${ }^{1}$, Oryza Pneumatica Inderasari, Khalifatul Syuhada \\ Universitas Mataram
}

\begin{abstract}
The problem studied in this study is the exploitation of children in the tradition of horse racing in the Dompu community. The purpose of this study is to find out the form of expolocitation of children who act as child jockeys in community traditions in Dompu Regency, knowing the implications of parental parenting on the choice of being a child jockey in Dompu regency and knowing the potential implementation of child protection based on Law No. 35 of 2014 on child jockeys. This research uses a qualitative descriptive approach. The data collection techniques used are methods of observation, in-depth interviews and documentation. Analysis of data in this study in the form of narratives obtained during interview activities, as well as some documents related to research topics. Using the paradigm in social definition, with the theory used in this study is the social theory of Max Weber. The results of this study found that (1). A form of child exploitation that acts as a child jockey in the community tradition in Dompu Regency. Consisting of parental coercion, the risk of accidents of child jockeys, safety and health are threatened, educational challenges and an environment that is not conducive (2). Implications of parental parenting on the choice of being a child jockey in Dompu Regency. Consists of parenting models, family economic resources and hereditary habits (3). The potential implementation of child protection under Law number 35 of 2014 on child jockeys. Consisting of a system of resusing and protecting the use of child jockeys, government regulations related to the use of children as child jockeys and horse racing are used as tourism promotion sectors of Dompu Regency, becoming a characteristic of the Dompu Regency area.
\end{abstract}

Keywords : Exploitation, Child, Horse Racing Tradition

\begin{abstract}
Abstrak
Permasalahan yang dikaji dalam penelitian ini adalah eksploitasi anak dalam tradisi pacuan kuda pada masyarakat Dompu. Tujuan dilakukannya penelitian ini untuk mengetahui bentuk ekspoloitasi anak yang berperan sebagai joki cilik dalam tradisi masyarakat di Kabupaten Dompu, mengetahui implikasi pengasuhan orang tua terhadap pilihan menjadi joki cilik di Kabupaten Dompudan mengetahui potensi implementasi perlindungan anak berdasarkan Undang-undang Nomor 35 tahun 2014 pada joki cilik. Penelitian ini menggunakan pendekatan deskriptif kualitatif. Teknik pengumpulan data yang dipakai adalah metode observasi, wawancara mendalam dan dokumentasi. Analisis data dalam penelitian ini berupa narasi yang diperoleh ketika kegiatan wawancara, serta beberapa dokumen yang berkaitan dengan topik penelitian. Menggunakan paradigma definisi sosial, dengan teori yang digunakan dalam penelitian ini adalah teoritindakan sosial Max Weber. Hasil penelitian ini ditemukan bahwa: (1) Bentuk eksploitasi anak yang berperan sebagai joki cilik dalam tradisi
\end{abstract}

\footnotetext{
${ }^{1}$ akbartanjungjuraid@gmail.com
} 
masyarakat di Kabupaten Dompu. Terdiri dari paksaan orang tua, resiko kecelakaan joki cilik pacuan kuda, keselamatan dan kesehatan terancam, tantangan pendidikan dan lingkungan yang tidak kondusif, (2) Implikasi pengasuhan orang tua terhadap pilihan menjadi joki cilik di Kabupaten Dompu. Terdiri model pola asuh orang tua, sumber ekonomi keluarga dan kebiasaan turun-temurun, (3) Potensi implementasi perlindungan anak berdasarkan Undang-undang nomor 35 tahun 2014 pada joki cilik. Terdiri dari sistem pengandalian dan perlindungan penggunaan joki cilik pacuan kuda, peraturan pemerintah terkait penggunaan anak sebagai joki cilik pacuan kuda dan pacuan kuda dijadikan sebagai sektor promosi pariwisata Kabupaten Dompu, menjadi ciri khas daerah Kabupaten Dompu.

Kata Kunci : Eksploitasi, Anak, Tradisi Pacuan Kuda

\section{Pendahuluan}

Tradisi merupakan refleksi fenomena yang ada dalam kehidupan masyarakat, menjadi simbol identitas kolektif yang meyakinkan dan memperkuat loyalitas primodial suatu daerahnya, dipertahankan dari generasi ke generasi. Seperti dalam tradisi pacuan kuda atau yang dikenal dengan pacoa jara oleh masyarakat Dompu Pulau Sumbawa, adalah tradisi yang dipraktekkan dari generasi ke generasi (Wahid, 2011). Budaya masyarakat Pulau Sumbawa, khususnya Kabupaten Dompu, kuda memiliki arti penting bagi kehidupan masyarakat bahkan lebih dari sebagaimana fungsinya. Kuda sangat erat kaitannya dalam tradisi pacuan kuda, hal ini disebabkan adanya makna, nilai, fungsi sosial, budaya, politik, tertentu yang dapat membantu penganutnya dalam mengarungi eksistensi kehidupannya (Dwikayana, 2015).

Pacoa jara sebagai tradisi telah menjadi hiburan rakyat paling populer bagi masyarakat Pulau Sumbawa, khususnya Kabupaten Dompu, yang memiliki keunikan berbeda dengan perlombaan pacuan kuda pada umumnya (Dompu Bicara, 2012). Perlombaan pacuan kuda di Kabupaten Dompu yaitu menggunakan joki (penggendara kuda) cilik untuk menunggangi kuda selama perlombaan. Joki cilik tersebut berumur sekitar 7 sampai 10 tahun. Perlombaan pacuan kuda biasa diadakan pada hari kemerdekaan Republik Indonesia dan hari ulang tahun Kabupaten Dompu. 
Selain hari-hari besar tersebut, pelatihan pacuan kuda biasa dilaksanakan setiap hari minggu. Karena pada hari itu, pemilik kuda melatih kudanya di arena pacuan kuda (Dompu Bicara, 2012). Namun, tradisi pacoa jara justru bertentangan dengan undang-undang karena melibatkan eksploitasi fisik dan sosial bahkan melanggar hak asasi anak. Sesuai yang diatur dalam Undang-undang Nomor 35 Tahun 2014 Perubahan Atas Undang-undang Nomor 23 Tahun 2002 Tentang Perlindungan Anak, sehingga berdasarkan regulasi tersebut pacoa jara dikategorikan sebagai penyalahgunaan terhadap tenaga anak.

Keberadaan joki cilik, telah menjadi suatu ciri khas penanda atau ikon dari pacoa jara. Joki cilik dianggap sebagai "nyawa" bagi tradisi pacoa jara (Wahid, 2011). Tetapi keberadaannya seringkali dianggap nihil atau sering dimanfaatkan atas nama tradisi, seperti banyak kasus sebagai motif pemanfaatan anak yang sering terjadi. Kegiatan ini bertentangan dengan konstitusi yang terdapat pada pasal 28 B Undang-undang Dasar 1945 bahwa setiap anak berhak atas kelangsungan hidup, tumbuh, dan berkembang serta berhak atas perlindungan dari kekasaran dan diskriminasi.Joki cilik terancam putus sekolah, lingkungan yang tidak baik karena arena perlombaan dimanfaatkan sebagai tempat judi. Serta sering terjadi kecelakaan jatuh dari kuda bahkan menyebabkan adanya korban kematian dalam tradisi pacuan kuda ini.

Berbeda dengan pacuan kuda pada umumnya yang menggunakan joki dewasa, olahragawan, berpakaian lengkap, bersepatu hak, berhelm, dan memiliki pelana sebagai alat penyokong untuk penuggang. Joki cilik di Kabupaten Dompu hanya seusia anak-anak Sekolah Dasar (SD), dengan pakaian seadanya, berhelm kecil, tidak menggunakan sepatu, berkaos kaki bola, dan tidak menggunakan pelana. Mereka hanya mengandalkan kekuatan mengapit dengan paha ditopang oleh pegangan satu tangan di tali kekang 
atau surai kuda dan aksesoris yang dikenakan di bagian kepala kuda. Pacoa jara dengan menggunakan joki cilik merupakan tradisi turun-temurun yang khas dan unik (Wahid, 2011).

Keterampilan menjadi joki cilik bukan perkara yang mudah, mereka ditempa sedemikian rupa oleh orang tua dan lingkungan sosialnya sehingga memiliki ketahanan fisik, ketangkasan, dan kenekatan jiwa yang melebihi anak-anak seusia mereka. Ketika anak-anak tersebut menjadi joki cilik, mereka terbentur dengan sejumlah resiko dalam pekerjaannya yakni masalah pendidikan serta kesehatannya. Mereka harus terbengkalai sekolahnya, menghadapi kekerasan fisik dan mental di arena pacuan kuda, dan resiko kecelakaan (LPA Kabupaten Dompu, 2010). Hal ini diduga minimnya atau kurangnya kesadaran dari orang tua yang memberikan pengajaran kepada anak merupakan faktor utama. Hal ini juga bertentangan dengan konstitusi negara pasal 31 ayat 1 yang berbunyi setiap warga negara berhak mendapat pendidikan lebih spesifik dan komprehensif telah diatur dalam Undangundang Nomor 35 Tahun 2014 Tentang Perlindungan Anak. Akan tetapi dalam aktivitas joki cilik ini juga, diidentifikasi melanggar Undang-undang Nomor 35 Tahun 2014 tentang perlindungan anak.

Hasil telaah referensi menjelaskan bahwa Joki cilik merupakan sebuah aktivitas yang dilakukan oleh anak dengan sepengetahuan orangtuanya, bahkan keterampilan mengendarai kuda diwariskan oleh orangtua dan lingkungannya. Hal ini telah menjadi tradisi yang membudaya, di dalam kehidupan masyarakat Dompu. Fenomena joki cilik menjadi sebuah dilema budaya, terbentuknya realitas joki cilik, paradoks pengasuhan dalam keluarga. Dugaan eksploitasi dalam tradisi masyarakat Dompu, menarik untuk diungkapkan secara ilmiah. Hal ini menjadi perhatian penting bagi peneliti untuk melakukan penelitian dengan judul,"Eksploitasi Anak dalam Tradisi Pacuan Kuda Pada Masyarakat Dompu”. 
Pemikiran teori tindakan sosial Max Weber, tindakan sosial dapat diartikan sebagai tindakan yang dimiliki oleh setiap individu atau kelompok yang memiliki makna subyektif. Dimana setiap individu yang melakukan tindakan memiliki motif atau tujuan tersendiri yang dipahami oleh Weber sendiri mengenai tindakan sosial, yang mana di dalamnya memang terkait dengan motif (dorongan) karena suatu tindakan pasti ada motif yang menyertainya. Weber secara khusus mengklasifikasikan tindakan sosial yang memiliki arti-arti subjektif tersebut, kedalam 4 (empat) tipe yang semakin rasional tindakan sosial itu semakin mudah dipahami (Ritzer George. 2008). Diantaranya yaitu tindakan rasionalitas instrumental (zwerk rational), tindakan rasional nilai (werk rational), tindakan afektif (affectual action) dan tindakan tradisional (traditional action).

Paradigma ini diambil dari salah satu aspek dari pemikiran Max Weber, yakni tentang tindakan sosial (Ritzer, 2008). Perkembangan dari hubungan sosial dapat pula diterangkan melalui tujuan tujuan-tujuan dari manusia yang melakukan hubungan sosial itu dimana ketika ia mengambil manfaat dari tindakan itu sendiri dalam tindakannyamemberikan perbedaan makna kepada tindakan itu sendiri. Menekankan pada realitas sosial bersifat subjektif, eksistensi realitas sosial tidak terlepas dari individu sebagai aktor yang melakukan suatu tindakan. Melalui paradigma ini, tindakan sosial berusaha untuk dipahami dan diinterpretasikan secara subjektif. Untuk menganalisis "Eksploitasi Anak dalam Tradisi Pacuan Kuda Pada Masyarakat Dompu". 


\section{Metode Penelitian}

Metode yang digunakan dalam penelitian ini adalah kualitatif deskriptif, pendekatan yang digunakan dalam penelitian ini adalah kualitatif. Pendekatan kualitatif digunakan untuk meneliti kondisi obyek yang alamiah, (sebagai lawannya adalah eksperimen) dimana peneliti adalah sebagai instrumen kunci. Lokasi penelitian kawasan sekitar arenaa pacuan kuda tradisional di Desa Kempo, Kecamatan Kempo, Kabupaten Dompu. Lingkup analisis dalam penelitian ini adalah joki cilik, pengasuhan orang tua joki cilik dan implementasi perlindungan anak berdasarkan undang-undang nomor 35 tahun 2014 pada joki cilik dari pemerintah terkait. Penentuan informan ini dilakukan dengan teknik purposive sampling, Adapun informan penelitan diantarannya joki cilik, orang tua joki cilik, pemilik kuda, masyarakat sekitar pacuan kuda dan pemerintah terkait. Data yang diperlukan berasal dari data primer yang didapatkan langsung dari informan dan data sekunder dari literartur dan buku. Teknik pengumpulan data yakni snowball (bola salju) dan triangulasi data diantaranya observasi, wawancara dan dokumentasi. Teknik analisis data yang digunakan dalam penelitian ini adalah reduksi data, penyajian data dan penarikan kesimpulan dari Miles dan Huberman.

\section{Hasil dan Pembahasan}

Permasalahan eksploitasi anak pada joki cilik dalam tradisi pacuan kuda, dapat dikaji dengan teori tindakan sosial Max Weber. Menurut Weber tindakan sosial dapat diartikan sebagai tindakan yang dimiliki oleh setiap individu atau kelompok yang memiliki makna subyektif. Dimana setiap individu yang melakukan tindakan memiliki motif atau tujuan tersendiri yang dipahami oleh Weber sendiri mengenai tindakan sosial, yang mana di dalamnya memang terkait dengan motif (dorongan) karena suatu tindakan pasti ada motif yang menyertainya. Weber secara khusus mengklasifikasikan 
tindakan sosial yang memiliki arti-arti subjektif tersebut, dalam 4 (empat) tipe yang semakin rasional tindakan sosial itu semakin mudah dipahami (Ritzer, 2008).

Klasifikasi atau tipe terdiri dari tindakan afektif (affectual action), yaitu di analisis terhadap anak yang berperan sebagai joki cilik. Dilakukan karena paksaan orang tuanya, yang bekerja atau terpaksa mencari nafkah untuk dirinya sendiri dan keluarganya, karena ancaman dari orientasi emosional orang tua yang akan memukul anaknya kalau tidak mengikuti latihan kuda atau perlombaan pacuan kuda. Jika tidak megikuti latihan kuda atau perlombaan pacuan kuda, seperti yang dikatakan oleh joki cilik ZDN:

"Iyo tasa'e kalau mada wati ne'e jara re, mada rena ma'ba pa ama mada tajadi mada re patu ngahi naa niii.Mada rau na'e nawa rau ipi deka paksa re, bahkan ku nanggi rau”.

Artinya: Iya bang kalau saya tidak mau naik kuda, saya dipukul sama ayah jadi saya ikutin aja perintahnya. Saya juga marah kalau dia terus paksa, bahkan saya sampai menanggis juga (wawancara ZDN, 17 Maret 2021).

Tapi dari orang tua joki cilik menerapkan hal tersebut agar membuat anaknya menjadi kuat dan berani, tidak menjadi anak yang manja ketika dewasa nanti. Sedangkan dari orientasi emosional seorang ibu, mempunyai perasaan takut dan empati dari resiko kecelakaan, tetapi karena budaya dan kebiasaan masyarakat membuat ibunya merelakan anaknya menunggang kuda.

Tipe tindakan rasional berdasarkan nilai (werk rational), dilakukan untuk alasan-alasan dan tujuan-tujuan yang kaitanya dengan nilai-nilai. Diyakini secara personal tanpa mempertimbangkan prospek-prospek yang ada, hal ini berkaitan resiko yang diterima dari pacuan kuda, mulai dari kecelakaan jatuh dari kuda dan bahkan korban jiwa. Membuat keselamatan dan kesehatan terancam, yang membahayakan kesehatan bahkan nyawanya. Seperti yang disampaikan oleh pemilik kuda pacuan MT, sebagai berikut: 
"Ede siwaura takdir ni ari ando kabune ku, kalau luka-luka re kita tinggal kasih uang. Untuk joki cilik yang meninggal kita kasih uang doannya sampai 44 harinya, pokoknya itu sudah resiko dou ma nente jara ni."

Artinya: Itu sudah takdir dek harus bagaimana lagi, kalau luka-luka itu kita tinggal kasih uang. Untuk joki cilik yang meninggal kita kasih uang doannya sampai 44 harinya, pokoknya itu sudah resiko menjadi joki ciliknya. (wawancara MT 15 Maret 2021).

Serta adanya tantangan pendidikan bagi joki cilik, dimana orang tua joki cilik rela meminta ijin terlebih dahulu ke pihak sekolah untuk kegiatan pacuan kudanya. Ditambah lagi dengan kondisi lingkungan yang tidak kondusif bagi perkembangan anak, seperti tindakan kriminalitas yang mempengaruhi mental dan tubuh kembang anak. Tetapi hal tersebut dilakukan oleh orang tua joki cilik, sebagai pendidikan kepada anaknya. Supaya tetap taat, berbakti dan patuh terhadap perintah orang tua. Sekaligus dari tradisi pacuan kuda ini, melatih fisik dan mental anaknya agar menjadi anak yang kuat dan berani. Serta dari, Tindakan rasionalitas instrumental (zwerk rational), ditujukan pada pencapaian tujuan-tujuan yang secara rasional diperhitungkan dan diupayakan sendiri oleh aktor yang bersangkutan.

Dalam hal ini menurut temuan penelitian yang dilakukan, bahwa tindakan joki cilik tersebut karena membantu sumber tambahan ekonomi keluarga. Sebagai pemenuhan kebutuhan keluarganya, yang disebabkan oleh faktor kemiskinan. Ditambah tindakan rasionalitas instrumental melandaskan diri kepada pertimbangan-pertimbangan yang rasional, ketika menanggapi lingkungan ekternalnya dan juga menanggapi orang-orang lain di luar dirinya dalam rangka usahanya untuk memenuhi kebutuhan atau tujuannya. Implementasi terjabar di dalam usaha atau tujuan pengendalian dan perlindungan joki cilik pacuan kuda oleh pemerintah, berdasarkan undangundang nomor 35 tahun 2014 pada joki cilik. Untuk menanggapi lingkungan 
ekternal atau lingkungan pacun kuda, berdasarkan temuan penelitian bahwa tanggapan pemerintah Desa Kempo.Bahwa belum ada langkah pengendalian dan perlindungan untuk mengatasi permasalahan joki ciliknya, karena masyarakat mengangap hal biasa untuk masalah ini.

Dinas Pemberdayaan Perempuan dan Perlindungan Anak Kabupaten Dompu, memberikan tanggapan bahwa belum ada penanganan secara khusus untuk masalah joki cilik ini, karena sistem dari dinas tersebut menerima laporan dari masyarakat untuk melakukan upaya pencegahan dan pemberdayaan. Menggenai tanggapan pengunaan joki cilik di arena pacuan yaitu sebagai berikut:

"Dari kami belum ada penanganan secara khusus joki cilik ini, karena sistem kami di Dinas Perberdayaan Perempuan dan Perlindungan Anak, menerima laporan dari masyarakat dan turun untuk melakukan pencegahan. Sebab penggunaan joki cilik di Kabupaten Dompu sudah menjadi budaya dan masalah bagi kami yang memang sulit di atasi. Dari Dinas Perberdayaan Perempuan dan Perlindungan Anak akan segera melakukan tindakan untuk membantu permasalahan joki ini karena merupakan masalah yang sudah menjadi budaya dari dulu."(wawancara 9 Maret 2021).

Karena penggunaan joki cilik sudah menjadi budaya yang sulit diatasi sebab sudah menjadi tradisi atau kebiasaan di masyarakat. Namun Dinas Pemberdayaan Perempuan dan Perlindungan Anak Kabupaten Dompu, segera melakukan tindakan untuk membantu melakukan upaya pengendalian dan perlindungan anak yang berprofesi sebagai joki cilik. Dalam hal ini Dinas Perberdayaan Perempuan dan Perlindungan Anak Kabupaten Dompu, mengajak peneliti untuk membantu melihat dan menemukan solusi dari masalah ini. Sedangkan tanggapan dari Dinas Kebudayaan dan Pariwisata Kabupaten Dompu, dari temuan penelitian menggenai peraturan pemerintah terkait penggunaan anak sebagai joki cilik pacuan kuda. Sedangkan dari Dinas Kebudayaan dan Pariwisata Kabupaten Dompu, memberi tanggapan 
dari implementasi perlindungan anak berdasarkan Undang-undang nomor 35 tahun 2014 pada joki cilik pacuan kuda di Kabupaten Dompu.

Bahwa Dinas Kebudayaan dan Pariwisata Kabupaten Dompu belum membuat peraturan daerah mengenai pengendalian dan perlindungan anak, yang berprofesi sebagai joki cilik pacuan kuda. Tetapi kedepannya Dinas Kebudayaan dan Pariwisata Kabupaten Dompu akan melakukan kordinasi dengan dinas terkait. Untuk membuat peraturan khusus daerah menggenai perlindungan joki cilik, karenapemerintah Kabupaten Dompu akan mengupayakan membuat peraturan pengendalian dan perlindungan joki cilik, dan himbauan dari pemerintah menggunakan pelengkapan perlindungan keamanan untuk joki cilik dalam tradisi pacuan kuda.

Tambahan dari Dinas Perberdayaan Perempuan dan Perlindungan Anak Kabupaten Dompu, menggenai pendapat dari implementasi regulasi Undang-undang Nomor 35 Tahun 2014 tentang perlindungan anak dengan pengunaan joki cilik ini di Kabupaten Dompu. Bahwa pemerintah menyadari terhadap undang-undang tersebut, Dinas Perberdayaan Perempuan dan Perlindungan Anak Kabupaten Dompu. Hanya melakukan sosialisasi secara umumnya saja, belum terlalu detail dalam menyelesaikan masalah joki cilik ini. Karena tradisi pacuan kuda telah menjadi budaya yang sudah dianggap biasa bagi masyarakat Desa Kempo, Kecamatan Kempo, Kabupaten Dompu. Sedangakan,

Tindakan tradisional (traditional action), dalam tindakan jenis ini memperlihatkan perilaku tertentu karena kebiasaan yang diperoleh dari nenek moyang yang sudah turun-temurun dalam memilihara kuda, tanpa refleksi yang sadar atau perencanaan. Seperti pernyataan dari Dinas Kebudayaan dan Pariwisata Kabupaten Dompu, yang menggatakan bahwa: 
"Itu sudah tradisi dalam masyarakat Kabupaten Dompu sejak zaman kesultanan, bertahan sampai dengan sekarang ini. Makanya pemerintah mendukung kegiatan ini dengan penyediaan dan perawatan fasilitas arena pacuan kuda" (wawancara 9 Maret 2021).

Berdasarkan temuan penelitian bahwa, pacuan kuda merupakan tradisi yang sejak dulu diadakan sampai dengan sekarang ini pada masyarakat Dompu yang di jadikan warisan turun temurun dan dipertahankan. Dari tradisi tersebut mempengaruhi sistem pengasuhan orang tua, sehingga orang tua menjadikan pilihan anak-anaknya menjadi joki cilik.

Karena faktor keturunan keluarga yang turun-temurun memelihara kuda pacuan dan menggunakan jasa joki ciliknya, serta temuan penelitian bahwapacuan kuda dijadikan sebagai promosi atau ikon pariwisata budaya bagi daerah Kabupaten Dompu. Hal ini merupakan program dari Dinas Kebudayaan dan Pariwisata Kabupaten Dompu, menjadikan pacuan kuda sebagai ciri khas wisata budaya di Kabupaten Dompu. Sebab tradisi pacuan kuda ini dilakukan secara turun-temurun dari zaman kesultanan Dompu, yang terus dipertahankan sampai sekarang ini.

\section{Kesimpulan}

Berdasarkan hasil penelitian peneliti mendapatkan data-data yang dapat disimpulkan sebagai berikut:

1. Bentuk eksploitasi anak yang berperan sebagai joki cilik dalam tradisi masyarakat di Kabupaten Dompu.Terdiri dari paksaan orang tua, dimana anak-anak yang berprofesi sebagai joki cilik, terpaksa bekerja mencari nafkah untuk dirinya sendiri dan keluargannya. Serta menerima bentuk kekerasaan, dengan cara dipukul agar anaknya menggikuti kemauan dari orang tua tersebut. Tapi dari orang tua joki cilik, menerapkan hal tersebut agar membuat anaknya menjadi kuat dan berani. Serta Resiko yang diterima dari pacuan kuda, mulai dari kecelakaan jatuh dari kuda dan 
bahkan korban jiwa. Membuat keselamatan dan kesehatan terancam, yang membahayakan kesehatan bahkan nyawanya. Serta adanya tantangan pendidikan bagi joki cilik, ditambah lagi dengan kondisi lingkungan yang tidak kondusif bagi perkembangan anak.

2. Implikasi pengasuhan orang tua terhadap pilihan menjadi joki cilik di Kabupaten Dompu. Terdiri dari model patuh pada orang tua, dimana orang tua joki cilik mengajarkan untuk selalu taat dan patuh terhadap perintah orang tuanya, supaya anak berbakti kepada orang tuanya. Orang tua joki cilik juga memperhatikan jadwal untuk joki cilik. Serta profesi sebagai joki cilik dijadikan sumber ekonomi bagi keluarganya, untuk membantu pemenuhan kebutuhan keluarga joki cilik. Tradisi pacuan kuda mempengaruhi sistem pengasuhan orang tua, sehingga orang tua menjadikan pilihan anak-anaknya menjadi joki cilik. Karena faktor keturunan keluarga yang turun-temurun memelihara kuda pacuandan menggunakan jasa joki ciliknya

3. Potensi implementasi perlindungan anak berdasarkan Undang-undang Nomor 35 tahun 2014 pada joki cilik. Terdiri dari sistem pengandalian dan perlindungan penggunaan joki cilik pacuan kuda, dari dinas terkait belum melakukan upaya-upaya terkait pengendalian dan perlindungan anak pada joki cilik, tetapi dari pemerintah Kabupaten Dompu akan mengupayakan membuat peraturan pengendalian dan perlindungan joki cilik dan himbauan dari pemerintah menggunakan pelengkapan perlindungan keamanan untuk joki cilik dalam tradisi pacuan. Peraturan pemerintah terkait penggunaan anak sebagai joki cilik pacuan kuda belum ada dalam bentuk peraturan daerah Kabupaten Dompu, terkait penyelesaian dari masalah joki cilik. Sebab masyarakat menganggap biasa pada masalah ini, yang juga didukung oleh pemerintah menjadikan pacuan kuda sebagai sektor promosi pariwisata Kabupaten Dompu. 


\section{Daftar Pustaka}

Anggraini, Minawati; Nurjannah, Siti; Inderasari, Oryza Pneumatica. 2020. Fenomena Pekerja Anak (Kasus Pedagang Asongan Anak di Kawasan Ekonomi Khusus Mandalika, Lombok Tengah). Jurnal Resiprokal 2(1)

Cipta, Adi. 2018. Pemanfaatan Joki Cilik Pada Tradisi Main Jaran (Pacuan Kuda) di Kabupaten Sumbawa (Perspektif Berdasarkan Undang-Undang Nomor 35 Tahun 2014 Perubahan Atas Undang-Undang Nomor 23 Tahun 2002 Tentang Perlindungan Anak. Fakultas Hukum Universitas Mataram

Dwikayana, Kadek. 2015. Pacoa Jara di Kabupaten Bima Nusa Tenggara Barat. Denpasar: Balai Pelestarian Nilai Budaya Bali, NTB, NTT.

Gunarsa, S.D \& Gunarsa, Y.S.D. 2008. Psikologi Perkembangan Anak dan Remaja. Jakarta: PT. BPK Gunung Mulia

Gunawan S.G. 2007. Farmakologi dan Terapi. Departemen Farmakologi dan Terapeutik Fakultas Kedokteran Universitas Indonesia.

Hanafi, Ahmad. 2017. Eksploitasi Anak Dibawah Umur Sebagai Bentuk Penyimpangan Sosial (Studi Kasus Anak Penjual Koran Disekitar Lampu Merah Bandar Lampung). Jurusan Sosiologi Fakultas Ilmu Sosial dan Ilmu Politik Universitas Lampung

Hidayat, Taufik. 2010. Mendidik dengan 4 Prinsip Konvensi Hak Anak. https://www.kompasiana.com/taufik,sawang/54ffa766a333110f455112be/m endidik-dengan-4-prinsip-konvensi-hak-anak. (Diakses Pada 28 November 2020, pukul 14.10 Wita).

Moleong, Lexy J. 2017. Metodologi Penelitian Kualitatif. Bandung: PT Remaja Rosdakarya.

Redaksi Dompu Bicara. 2012. Pacuan Kuda. https://www.dompubicara.com. (Diakses tanggal 25 November 2020, pukul 09.40 Wita).

Ritzer, Goorge. 2012. Teori Sosiologi. Yogyakarta: Pustaka Pelajar.

Ritzer. George. 2008. Teori Sosiologi dari Teori Sosiologi Klasik sampai Perkembangan Mutakhir Teori Sosial Postmodern. Bantul: Kreasi Wacana.

Saleh, Syaiful \& Akhir, Muhammad. 2016. Eksploitasi Pekerja Anak Pemulung. Equilibrium: Jurnal Pendidikan Sosiologi

Setiady, Tholib. 2010. Pokok-Pokok Hukum Penitensier Indonesia. Bandung: Alfabeta.

Soetarso. 1999. Praktik Pekerjaan Sosial. Bandung: Kopma STKS Bandung.

Sugiyono. 2008. Memahami Penelitian Kualitatif. Bandung: Alfabeta.

Sugiyono. 2013. Metode Penelitian Kuantitatif, Kualitatif, Dan Kombinasi (Mixed Methods). Bandung: Alfabeta.

Sugiyono. 2018. Metode Penelitian Pendidikan Pendekatan Kuantitatif, Kualitaitf, dan $R \& D$. Bandung: Alfabeta. 
Suherman, Maman. 2014. Kajian Tentang Perilaku Siswa dalam Salat Jumat. Universitas Pendidikan Indonesia

Tridhonanto, Al \& Agency, Beranda. 2014. Mengembangkan Pola Asuh Demokratis. Jakarta: PT Gramedia.

Undang-Undang Dasar Negara Republik Indonesia 1945, Pasal 28 Tentang Hak Asasi Manusia.

Undang-Undang Dasar Negara Republik Indonesia 1945, Pasal 31 Tentang Pendidikan.

Undang-Undang RI Nomor 35 Tahun 2014 Perubahan Atas Undang-Undang Nomor 23 Tahun 2002 Tentang Perlindungan Anak.

Wahid, Aba D. 2011. Jara Mbojo: Kuda-kuda Kultural. Mataram: Dinas Kebudayaan dan Pariwisata Provinsi Nusa Tenggara Barat

Yasin, Ilyas. 2019. Ketua LPA Desak Joki Cilik di Dompu dan di Bima Ditiadakan. https://kumparan.com/infodompu/ketua-lpa-desak-joki-cilikdidompu-danbima-ditiadakan-1s4S1sSqYjf/full. (Diakses 17 Oktober 2020, pukul 08:20 WITA). 